\title{
Aplicação Tardia de Glyphosate e Estande e Desenvolvimento InICIAL do Arroz em Sistema de Cultivo MínIMO ${ }^{1}$
}

\author{
Delayed Application of Glyphosate and Stand and Initial Growth of Rice Plants (Oryza sativa) \\ under a Minimum Tillage System
}

CRUSCIOL, C.A.C. ${ }^{2}$, LIMA, E.V. ${ }^{3}$, ANDREOTTI, M. ${ }^{4}$ e SCHIOCCHET, M.A. ${ }^{3}$

\begin{abstract}
RESUMO - O controle de plantas daninhas na cultura do arroz é ainda um problema, mesmo em cultivo mínimo, em razão do revolvimento do solo na linha de semeadura, que proporciona o reaparecimento de infestantes. Assim, objetivou-se estudar o efeito do atraso da aplicação de glyphosate sobre a formação do estande e o desenvolvimento inicial das plantas de arroz cv. IAC 102 irrigado por inundação. O experimento foi conduzido sob túnel plástico, em caixas d'água de 500 L, contendo NEOSSOLO FLÚVICO Ta Eutrófico. O delineamento experimental foi o de blocos casualizados, com quatro repetições. Os tratamentos consistiram da aplicação de glyphosate: seis horas antes da semeadura do arroz (testemunha); no início da emergência; três dias após a emergência; e seis dias após, sem e com lâmina d'água. A dose do herbicida foi de 1.920 g i.a. ha ${ }^{-1}$. Para todas as variáveis analisadas houve efeito significativo dos tratamentos; aos 42 dias após a emergência, constatou-se que a testemunha foi estatisticamente superior, na formação do estande, na altura de plantas, no comprimento de raiz e na massa seca das partes aérea e de raiz, aos demais tratamentos em que ocorreram atrasos na aplicação do glyphosate.
\end{abstract}

Palavras-chave: dessecante, arroz irrigado.

\begin{abstract}
Weed control is still one of the most important problems of rice production, even under a reduced-tillage system. The purpose of this research was to study the effect of delayed application of glyphosate on paddy rice $c v$. IAC 102. The experiment was conducted under plastic tunnels with rice plants growing in water tanks of 500 liters of capacity, containing Alluvial soil. Treatments consisted of glyphosate application on the soil surface six hours before sowing, (control) at seedling emergence, three days after, and six days after, combined or not with water flooding. The experimental design was a randomized block with four replications and the herbicide dosage was $1,920 \mathrm{~g}$ a.i. $\mathrm{ha}^{-1}$. There was a significant effect of the treatments on the variables studied. The results showed that the control treatment (when glyphosate was applided six hours befores sowing) was statistically superior to the other treatments in stand formation, plant height, root length and plant/root dry matter.
\end{abstract}

Key words: desiccant, flood-irrigated rice.

\section{INTRODUÇÃO}

O arroz (Oryza sativa L.) é o principal alimento para a maioria da população mundial, constituindo-se, juntamente com o trigo e o milho, no cereal mais produzido no mundo (Agostinetto et al., 2001).
A produtividade de grãos do arroz irrigado por inundação no Brasil, com média de $5.000 \mathrm{~kg} \mathrm{ha}^{-1}$ (Guimarães \& Santa'Ana, 1999), pode ser considerada baixa, quando comparada com a de outros países, principalmente os asiáticos. Esse resultado é decorrente de vários fatores, dentre os quais destaca-se a

Recebido para publicação em 21/8/2001 e na forma revisada em 15/3/2002.

2 Prof. Adjunto Dr., FCA-UNESP. Caixa Postal 237, 18603-970 Botucatu-SP; ${ }^{3}$ Eng.-Agr. M.S., FCA-UNESP, Botucatu-SP. ${ }^{4}$ Prof. Assistente Dr., CCA-UNIOESTE., 85960-000 Marechal Cândido Rondon-PR. 
interferência das plantas daninhas sobre o desenvolvimento da cultura. Ainda assim, a produtividade brasileira aumentou $12 \%$ na década de 90, em virtude da incorporação de tecnologias que, contudo, não foram suficientes em favorecer a expressão do potencial dos cultivares modernos, com capacidade produtiva superior a $8.000 \mathrm{~kg} \mathrm{ha}^{-1}$ (Yokoyama et al., 1999).

Uma das práticas para diminuir os problemas com as plantas daninhas na cultura do arroz é a adoção do sistema de cultivo mínimo, onde se conciliam as vantagens da semeadura direta com o emprego de algumas operações mínimas de preparo convencional do solo (Foloni et al., 1997). Nesse sentido, efetua-se o revolvimento inicial do solo, expondo as sementes viáveis das plantas daninhas, que, após a inundação da área, iniciam o processo de germinação (Foloni et al., 1997; Santos, 1999). Sobre as plantas daninhas emergidas faz-se o controle químico, de pré-semeadura, por meio de herbicida não-seletivo, de amplo espectro, com efeito residual curto e ação sistêmica, como aqueles à base de glyphosate (Dias \& Fleck, 1982). Em seguida, procede-se à realização da semeadura direta sobre a cobertura vegetal morta previamente dessecada (Fornasieri Filho \& Fornasieri, 1993a).

O emprego de glyphosate [N-(fosfonometil) glicina] como herbicida dessecante no cultivo mínimo é de conhecimento prático e científico, por exercer efetivo controle de grande número de plantas daninhas mono e dicotiledôneas, perenes e anuais, sem ser ambientalmente agressivo (Santos et al., 2001). Esse produto é de fácil absorção e de translocação pelo xilema e floema para as partes aérea e subterrânea, estando diretamente relacionado com a maior atividade fisiológica das plantas, isto é, com o pleno estádio vegetativo (Cobucci \& Noldin, 1999). Portanto, uma das primeiras etapas a serem obedecidas no emprego do herbicida diz respeito à época adequada de aplicação.

Foloni et al. (1997), após a semeadura do arroz, observaram que os herbicidas glyphosate e sulfosate, independentemente da dose utilizada, com ou sem adjuvante, aplicados 16 dias antes da semeadura da cultura, não provocaram qualquer fitotoxicidade aparente no arroz. Esses resultados foram confirmados pela avaliação do estande e da altura de plantas.
Entretanto, é sabido que a máxima eficiência do glyphosate ocorre até seis horas após a aplicação, sendo esse o período de tempo necessário para a máxima absorção, não havendo a ocorrência de chuvas. Assim, de acordo com Frizzo (1991), o herbicida dessecante utilizado no sistema de cultivo mínimo pode ser aplicado pelo menos seis horas antes da semeadura do arroz, que, em condições normais, seria suficiente para um bom controle das plantas daninhas, não havendo toxicidade à cultura, principalmente se a entrada de água na lavoura ocorrer até cerca de 10 dias após a emergência.

O controle de plantas daninhas do tipo gramíneas ainda se constitui em grande problema, mesmo no sistema de cultivo mínimo, requerendo aplicações mais eficientes de herbicida (Fleck et al., 1999). Esse fato é verificado, usualmente, após a semeadura do arroz, em razão do revolvimento do solo na linha de semeadura, onde normalmente ocorre o reaparecimento de plantas indesejáveis. Destaca-se o arroz vermelho como a espécie mais limitante ao aumento do potencial de rendimento (Souza \& Fischer, 1986), pois pertence à mesma espécie botânica do arroz cultivado, o que torna o seu controle difícil.

A possibilidade do emprego de glyphosate após a semeadura do arroz ou após a emergência desse cereal não foi efetivamente estudada. Essa informação teria grande importância como opção tecnológica até mesmo para o cultivo convencional, onde ocorre a reinfestação das plantas daninhas. Assim, independentemente do sistema de cultivo adotado, se houver a possibilidade da aplicação de glyphosate após a emergência das plantas de arroz, sem causar danos ao seu desenvolvimento, menor será a concorrência com as plantas daninhas.

Para isso, objetivou-se estudar o efeito do atraso da aplicação de glyphosate, em sistema de cultivo mínimo, sobre a formação do estande e o desenvolvimento inicial do arroz irrigado por inundação, visando maior eficiência no controle de plantas daninhas.

\section{MATERIAL E MÉTODOS}

O experimento foi conduzido no Departamento de Produção Vegetal - Setor de Agricultura e Melhoramento Vegetal, pertencente à 
Faculdade de Ciências Agronômicas - UNESP, no município de Botucatu-SP.

O delineamento experimental empregado foi o de blocos ao acaso, com quatro repetições. As parcelas foram representadas pelos seguintes tratamentos: 1- testemunha [aplicação de glyphosate seis horas antes da semeadura do arroz, conforme preconizado por Frizzo (1991)]; 2- aplicação de glyphosate no início da emergência das plântulas de arroz (O DAE); 3- aplicação de glyphosate três dias após a emergência (3 DAE); 4- aplicação de glyphosate seis dias após a emergência, sem lâmina d'água (6 DAE-SL); e 5- aplicação de glyphosate seis dias após a emergência, com lâmina d'água de 5 cm (6 DAE-CL). A quantidade do produto comercial utilizado foi de $4 \mathrm{~L} \mathrm{ha}^{-1}$ (Roundup), de acordo com a recomendação de Silva (1996), ou seja, correspondendo à dose de $1.920 \mathrm{~g}$ i.a. ha ${ }^{-1}$, sem a adição de adjuvante. Utilizou-se pulverizador costal de precisão, com bicos de jato do tipo "leque" 110.03, mantendo-se pressão constante de $\mathrm{CO}_{2}$ a $120 \mathrm{kPa}$, proporcionando volume de aplicação de $150 \mathrm{~L} \mathrm{ha}^{-1}$.

O cultivar empregado foi o IAC 102, proveniente do Instituto Agronômico de CampinasSP. Ele Apresenta como principais características ciclo médio ( 125 a 135 dias), porte médio $(90$ a $100 \mathrm{~cm})$, boa resistência ao acamamento, resistência moderada à brusone (Pyricularia grisea), grãos longos, rendimento de grãos inteiros em torno de 55\% e produtividade variando de 4.000 a $7.000 \mathrm{~kg} \mathrm{ha}^{-1}$ (IAC, 1997).

O experimento foi instalado sob cobertura de túnel plástico com as laterais teladas, em caixas d'água de cimento-amianto com capacidade de $500 \mathrm{~L}$, com área útil de $1 \mathrm{~m}^{2}$ e profundidade efetiva de $30 \mathrm{~cm}$, contendo NEOSSOLO FLÚVICO Ta Eutrófico (EMBRAPA, 1999), retirado da camada arável $(0-20 \mathrm{~cm})$ de uma área de várzea. As caixas apresentavam entrada e saída de água individuais, com regulagem de admissão da lâmina de água por meio de torneiras e drenagem por tubos de PVC.

A preparação das caixas constituiu-se da aplicação de 3 t ha $^{-1}$ (300 g por caixa) de calcário dolomítico (Raij et al., 1985), para atenuar os efeitos de toxicidade por Fe, e revolvimento do solo, seguido de nivelamento com lâmina de água. A adubação mineral de semeadura constou de $10 \mathrm{~kg} \mathrm{ha}^{-1}$ de $\mathrm{N}, 40 \mathrm{~kg} \mathrm{ha}^{-1}$ de $\mathrm{P}_{2} \mathrm{O}_{5}$ e $40 \mathrm{~kg} \mathrm{ha}^{-1} \mathrm{de}_{2} \mathrm{O}$ (Raij et al., 1985).
A semeadura foi efetuada no dia 30/4/1996, em quatro linhas de $1 \mathrm{~m}$ por caixa, espaçadas de $20 \mathrm{~cm}$, depositando-se 50 sementes de arroz por fileira. A emergência ocorreu seis dias após a semeadura. As caixas foram mantidas com lâmina de água corrente de $10 \mathrm{~cm}$ a partir do perfilhamento. A adubação mineral de cobertura foi realizada aos 32 dias após a emergência, aplicando-se $40 \mathrm{~kg} \mathrm{ha}^{-1}$ de N (Raij et al., $1985)$, na forma de sulfato de amônio $(20 \%$ de $\mathrm{N}$ e $22 \%$ de $\mathrm{S}$ ). O experimento foi conduzido até os 42 dias após a emergência, quando as plantas se encontravam em pleno estádio vegetativo.

As variáveis analisadas foram as que se seguem.

\section{Estande da cultura}

Contou-se o número total de colmos do arroz por $\mathrm{m}^{2}$, na emergência, aos 18, 25 e 42 dias após a emergência, considerando-se somente os que estavam fixados e sadios.

\section{Altura de planta}

Medida realizada em $\mathrm{cm}$, considerando a distância média compreendida entre o nível do solo e a extremidade superior da última folha. Essa avaliação ocorreu aos 42 dias após a emergência, em 10 plantas seqüenciadas, de linha de semeadura previamente sorteada, menos as bordaduras.

\section{Comprimento de raiz}

Expresso em $\mathrm{cm}$ da região do colo até a extremidade do sistema radicular, após coleta e lavagem aos 42 dias após a emergência, seguindo o mesmo padrão de amostragem usado na determinação da altura de planta.

\section{Massa seca da parte aérea e de raiz}

Para determinação da produção de massa seca das partes aérea (MSA) e de raiz (MSR) foram aproveitadas as mesmas plantas utilizadas nas aferições de altura e comprimento radicular aos 42 dias após a emergência. As plantas foram lavadas e separadas em parte aérea e raízes, sendo colocadas em estufa com circulação forçada de ar a $60{ }^{\circ} \mathrm{C}$ até massa 
constante. Em seguida, determinou-se a massa do material em balança de precisão.

Os dados de cada variável analisada foram submetidos à análise de variância, sem transformação, com aplicação do teste F, sendo as médias dos tratamentos comparadas pelo teste de Tukey a 5\%. Efetuou-se, também, análise de regressão polinomial, ajustando-se as equações para os dados de número de colmos por $\mathrm{m}^{2}$ (estande) em função do tempo, sendo escolhidas as regressões com maior coeficiente $\left(R^{2}\right)$ dentre as significativas pelo teste $\mathrm{F}$. Todos os cálculos foram realizados por meio do programa de computador ESTAT, conforme método descrito por Banzato \& Kronka (1989).

\section{RESULTADOS E DISCUSSÃO}

A comparação entre as médias do estande de plantas de arroz na emergência encontrase na Tabela 1. Nessa primeira análise ainda não tinham sido aplicados os tratamentos 0 DAE, 3 DAE, 6 DAE-SL e 6 DAE-CL; assim, conseqüentemente, o valor de $\mathrm{F}$ não indicou significância. Dessa forma, a informação apresentada apenas serve como indicativo de que os estandes iniciais se encontravam uniformes para todos os tratamentos.

Tabela 1 - Estande da cultura do arroz (número de colmos por $\mathrm{m}^{2}$ ), na emergência, 18, 25 e 42 dias após a emergência (DAE), em função do atraso na aplicação de glyphosate, no sistema de cultivo mínimo. Botucatu-SP

\begin{tabular}{|l|c|c|c|c|}
\hline Tratamentos & Emergência & $18 \mathrm{DAE}$ & $25 \mathrm{DAE}$ & $42 \mathrm{DAE}$ \\
\hline Testemunha & $114 \mathrm{a}$ & $130 \mathrm{a}$ & $127 \mathrm{a}$ & $141 \mathrm{a}$ \\
0 DAE & $135 \mathrm{a}$ & $104 \mathrm{a}$ & $102 \mathrm{ab}$ & $101 \mathrm{~b}$ \\
$3 \mathrm{DAE}$ & $110 \mathrm{a}$ & $54 \mathrm{~b}$ & $49 \mathrm{~b}$ & $33 \mathrm{c}$ \\
6 DAE-SL & $127 \mathrm{a}$ & $92 \mathrm{ab}$ & $63 \mathrm{~b}$ & $21 \mathrm{c}$ \\
6 DAE-CL & $111 \mathrm{a}$ & $98 \mathrm{ab}$ & $68 \mathrm{ab}$ & $51 \mathrm{c}$ \\
\hline F & $2,79 \mathrm{~ns}$ & $7,50 * *$ & $5,41 *$ & $33,38 * *$ \\
\hline CV $(\%)$ & 11,03 & 21,08 & 33,54 & 25,10 \\
\hline DMS & 30 & 45 & 62 & 39 \\
\hline
\end{tabular}

Comparam-se letras na vertical. Médias seguidas das mesmas letras não diferem entre si pelo teste de Tukey a $5 \%$. ${ }^{*} \mathrm{e}^{* *}$ significativo a 5 e $1 \%$ pelo teste $\mathrm{F}$, respectivamente.

Pela Tabela 1, verifica-se, aos 18 dias após a emergência, que a testemunha e o tratamento o DAE foram estatisticamente superiores àquele em que o glyphosate foi aplicado aos
3 DAE. No entanto, o tratamento 3 DAE foi significativamente igual aos que receberam aplicação de glyphosate aos $6 \mathrm{DAE}$, sem ou com lâmina d'água, que não diferiram da testemunha e do tratamento 0 DAE.

Aos 25 dias após a emergência, comportamento semelhante ao mencionado foi observado (Tabela 1), em que a população de plantas da testemunha superou de forma significativa os tratamentos $3 \mathrm{DAE}$ e $6 \mathrm{DAE}-\mathrm{SL}$, que não diferiram da aplicação de glyphosate aos $0 \mathrm{DAE}$ e 6 DAE-CL, sendo estes últimos estatisticamente iguais à testemunha.

Nos 42 dias após a emergência (Tabela 1), constataram-se diferenças bem marcantes entre os estandes (número de colmos por $\mathrm{m}^{2}$ ), em que a testemunha, com aplicação de glyphosate seis horas antes da semeadura, proporcionou o melhor resultado, sendo superior aos demais tratamentos. Cabe ressaltar que, com a aplicação de glyphosate no início da emergência ( $0 \mathrm{DAE}$ ), houve a formação de estande superior aos tratamentos em que ocorreram maiores atrasos na aplicação, sem ou com lâmina d'água (Tabela 1). Portanto, as aplicações mais tardias, ou seja, 3 e 6 DAE, proporcionaram reduções mais acentuadas do número de colmos das plantas de arroz, isto é, diminuiu o estande da cultura.

Na Figura 1, os resultados dos estandes formados encontram-se apresentados por meio de regressão polinomial. A representação gráfica da equação para a testemunha mostra aumento linear no transcorrer do tempo, não havendo interferência do herbicida aplicado seis horas antes da semeadura. Entretanto, para os tratamentos 0 DAE e 3 DAE observou-se diminuição do estande, de forma quadrática. Já os tratamentos com o maior atraso na aplicação de glyphosate (6 DAE-SL e 6 DAE-CL) apresentaram queda linear do número de colmos do arroz.

Os resultados obtidos neste trabalho, com relação ao estande, mostraram que plantas de arroz que se apresentaram aparentemente normais, nas duas primeiras avaliações (18 e 25 dias após a emergência), na realidade podem estar com o metabolismo comprometido (Voll, 1993). Isso se deve ao efeito tóxico proporcionado pelo atraso na aplicação de glyphosate, que possui como uma de suas características 
a lenta visualização dos sintomas, somente observado de forma marcante, para o número de colmos, aos 42 dias após a emergência. Assim, mediante os resultados até então apresentados, acredita-se que o uso da dose de glyphosate indicada por Silva (1996), com aplicação na época recomendada por Frizzo (1991), provavelmente não vá influenciar negativamente a formação do estande para a cultura do arroz.

A Tabela 2 contém os resultados obtidos sobre a aferição de algumas unidades estruturais ligadas ao desenvolvimento das plantas. Constata-se que houve efeito significativo dos tratamentos aplicados, em todas as variáveis analisadas, aos 42 dias após a emergência. Os atrasos na aplicação de glyphosate, independentemente da época, diferiram estatisticamente da testemunha, com redução na altura das plantas, no comprimento de raízes e na produção de MSA e de MSR. Ressalta-se, por sua vez, que os tratamentos 0 DAE, 3 DAE, 6 DAE-SL e 6 DAE-CL não diferiram entre si (Tabela 2).

Especificamente quanto à variável altura de planta, a média de redução observada para os quatro tratamentos em que o herbicida foi aplicado a partir da emergência, comparado à testemunha, foi de aproximadamente $41 \%$. Esse resultado permite inferir que o glyphosate inibiu o crescimento caulinar, reduzindo a altura das plantas, fato esse verificado no presente trabalho (Tabela 2). Já para o comprimento de raiz a redução foi bem mais drástica, chegando a aproximadamente $65 \%$.

Tabela 2 - Altura de planta, comprimento de raiz, produção de massa seca da parte aérea (MSA) e de raiz (MSR) por planta aos 42 dias após a emergência (DAE), em função do atraso na aplicação de glyphosate, no sistema de cultivo mínimo. Botucatu-SP

\begin{tabular}{|l|c|c|c|c|}
\hline Tratamentos & $\begin{array}{c}\text { Altura de } \\
\text { planta } \\
(\mathrm{cm})\end{array}$ & $\begin{array}{c}\text { Compri- } \\
\text { mento de } \\
\text { raiz }(\mathrm{cm})\end{array}$ & $\begin{array}{c}\text { MSA } \\
(\mathrm{mg})\end{array}$ & $\begin{array}{c}\text { MSR } \\
(\mathrm{mg})\end{array}$ \\
\hline Testemunha & $15,9 \mathrm{a}$ & $21,9 \mathrm{a}$ & $138,2 \mathrm{a}$ & $78,4 \mathrm{a}$ \\
0 DAE & $8,9 \mathrm{~b}$ & $8,5 \mathrm{~b}$ & $22,5 \mathrm{~b}$ & $14,6 \mathrm{~b}$ \\
3 DAE & $8,6 \mathrm{~b}$ & $6,2 \mathrm{~b}$ & $17,0 \mathrm{~b}$ & $19,0 \mathrm{~b}$ \\
6 DAE-SL & $10,3 \mathrm{~b}$ & $7,2 \mathrm{~b}$ & $27,3 \mathrm{~b}$ & $20,5 \mathrm{~b}$ \\
6 DAE-CL & $9,8 \mathrm{~b}$ & $8,9 \mathrm{~b}$ & $25,1 \mathrm{~b}$ & $18,0 \mathrm{~b}$ \\
\hline F & $14,57 * *$ & $29,83 * *$ & $55,07 * *$ & $54,08 * *$ \\
\hline CV $(\%)$ & 14,55 & 22,27 & 30,26 & 24,47 \\
\hline DMS & 3,5 & 5,3 & 31,4 & 16,6 \\
\hline
\end{tabular}

Comparam-se letras na vertical. Médias seguidas das mesmas letras não diferem entre si pelo teste de Tukey a $5 \%$. $* \mathrm{e} * *$ significativo a 5 e $1 \%$ pelo teste $\mathrm{F}$, respectivamente.

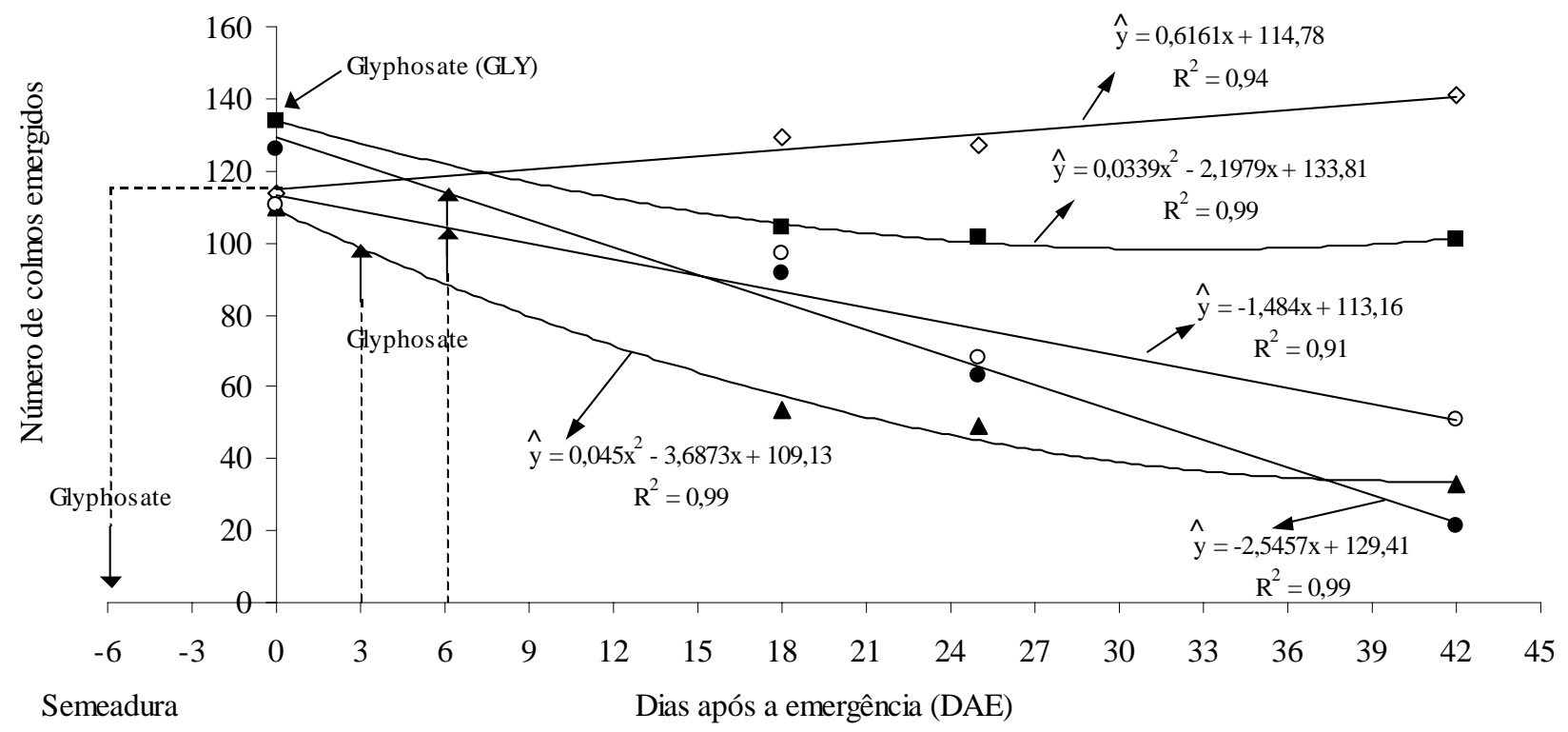

Figura 1 - Número de colmos de arroz por $\mathrm{m}^{2}$ (estande), em função da época de aplicação de glyphosate (GLY) e de dias após a emergência (DAE), sendo $\diamond$ Testemunha (GLY 6 horas antes da semeadura); 0 DAE (GLY na emergência); $\mathbf{\Delta}$ DAE (GLY sem lâmina d'água); • 6 DAE-SL (GLY sem lâmina d'água); e $\bigcirc 6$ DAE-CL (GLY com lâmina d'água de $5 \mathrm{~cm}$ ), em que $(\mathrm{GLY} \rightarrow)$ significa o momento da aplicação de GLY. Botucatu-SP. 
O maior prejuízo ao comprimento radicular, em comparação com a altura de planta, pode ser justificado pela aplicação do glyphosate durante o pleno estádio vegetativo das plantas de arroz. Isso, segundo Voll (1993), faz com que o herbicida, ao chegar na corrente floemática, seja direcionado, em grande parte, aos órgãos subterrâneos, inibindo o crescimento das raízes e o armazenamento de carboidratos, chegando a matar a gema radicular.

Em contrapartida, para a produção de massa seca, com aplicação de glyphosate nas épocas não preconizadas pela literatura, prejuízos mais acentuados foram verificados na parte aérea, ou seja, em relação à testemunha, ocorreu redução média de aproximadamente 83\%, enquanto a MSR decresceu em torno de $77 \%$.

O glyphosate, por ser um herbicida de ação sistêmica, apresenta sua melhor eficiência relacionada com a maior atividade fisiológica das plantas, sendo a relação elevada entre parte aérea e raiz favorável (IRGA, 1995). Portanto, como as plantas de arroz até a idade de 7 a 8 dias após a emergência, ou mais especificamente até a saída da quarta folha, apresentam pequena área foliar e utilizam as reservas contidas no endosperma (Fornasieri Filho \& Fornasieri, 1993b), acreditava-se na possibilidade de que, em cultivo mínimo, a aplicação de glyphosate pudesse ser atrasada para o período em questão, não acarretando problemas na emergência e no desenvolvimento inicial do arroz.

A hipótese de trabalho não foi confirmada, de acordo com os dados apresentados e discutidos, levando-se à inferência de que houve absorção de glyphosate e sua atuação metabólica efetiva no estádio de emergência das plantas de arroz, afetando a formação dos estandes (Tabela 1) e o número de unidades estruturais (Tabela 2). Assim, confirma-se a recomendação de Frizzo (1991), de que o herbicida dessecante seja aplicado seis horas antes da semeadura.

Deve-se também salientar a necessidade de novos estudos com a aplicação de glyphosate após a semeadura, mas antes da emergência das plantas de arroz, pois no solo espera-se que o produto seja rapidamente adsorvido aos colóides, tornando-se indisponivel, além do fato de que a degradação por microrganismos ocorre em poucos dias, gerando produtos não-fitotóxicos, sendo por isso considerado um produto não-persistente (Dias \& Fleck, 1982; Cobucci \& Noldin, 1999).

\section{LITERATURA CITADA}

AGOSTINETTO, D.; FLECK, N. G.; MENEZES, V. G. Herbicidas não seletivos aplicados na fase de maturação do arroz irrigado. Sci. Agric., v.58, n.2, p.277-285. 2001.

BANZATO, D. A.; KRONKA, S. N. Experimentação agrícola. Jaboticabal: Fundação Estudos e Pesquisas em Agronomia, Medicina Veterinária e Zootecnia, 1989. 247p.

COBUCCI, T.; NOLDIN, J. A. Plantas daninhas e seu controle. In: VIEIRA, N. R. A.; SANTOS, A. B.; SANT'ANA, E. P. (Eds.) A cultura do arroz no Brasil. Santo Antônio de Goiás: EMBRAPA Arroz e Feijão, 1999. p. 375-415.

DIAS, C. A.; FLECK, N. G. Efeitos dos herbicidas glyphosate e paraquat, aplicados ao solo, sobre a emergência de feijão e soja e de algumas espécies daninhas. Planta Daninha, v. 5, n. 1, p. 23-34. 1982.

EMPRESA BRASILEIRA DE PESQUISA AGROPECUÁRIA - EMBRAPA. Centro Nacional de Pesquisa de Solos. Sistema Brasileiro de Classificação de Solos. Brasília: 1999. 412 p.

FLECK, N. G. et al. Efeitos de parâmetros de aplicação na ação dessecante do herbicida sulfosate sobre plantas de arroz. Planta Daninha, v. 17, n. 1, p. 139-149, 1999.

FOLONI, L. L.; RODRIGUES, J. D.; ONO, E. O. Controle do arroz vermelho através do herbicida sulfosate isolado e em mistura com adjuvante. Planta Daninha, v. 15, n. 1, p. 39-45, 1997.

FORNASIERI FILHO, D.; FORNASIERI, J. L. Técnica cultural. In: FORNASIERI FILHO, D.; FORNASIERI, J. L. (Eds.) Manual da cultura do arroz. Jaboticabal: Fundação Estudos e Pesquisas em Agronomia, Medicina Veterinária e Zootecnia, 1993a. p. 78-116.

FORNASIERI FILHO, D.; FORNASIERI, J. L. Crescimento e Desenvolvimento. In: FORNASIERI FILHO, D.; FORNASIERI, J. L. (Eds.) Manual da cultura do arroz. Jaboticabal: Fundação Estudos e Pesquisas em Agronomia, Medicina Veterinária e Zootecnia, 1993b. p. 21-41.

FRIZZO, C. Plantio direto e plantio direto com cultivo mínimo de arroz irrigado. Lav. Arroz., v. 44, n. 398, p. 3031, 1991. 
GUIMARÃES, E. P.; SANT'ANA, E. P. Sistemas de cultivo. In: VIEIRA, N. R. A.; SANTOS, A. B.; SANT'ANA, E. P. (Eds.) A cultura do arroz no Brasil. Santo Antônio de Goiás: EMBRAPA Arroz e Feijão, 1999. p.17-35.

INSTITUTO AGRONÔMICO DE CAMPINAS - IAC. Cultivares elite. Campinas: 1997. 57 p.

INSTITUTO RIO-GRANDENSE DO ARROZ - IRGA. Arroz irrigado: recomendações técnicas da pesquisa para o sul do Brasil. In: REUNIÃO DA CULTURA DO ARROZ IRRIGADO, 21, 1995, Porto Alegre. Anais... Porto Alegre: 1995. 88p.

RAIJ, B. van et al. Recomendação de adubação e calagem para o estado de São Paulo. Campinas: Instituto Agronômico de Campinas, 1985. 107 p.

SANTOS, A. B. Sistemas de plantio. In: VIEIRA, N. R. A.; SANTOS, A. B.; SANT'ANA, E. P. (Eds.) A cultura do arroz no Brasil. Santo Antônio de Goiás: EMBRAPA Arroz e Feijão, 1999. p.354-374.
SANTOS, I. C. et al. Eficiência de glyphosate no controle de Commelina benghalensis e Commelina diffusa. Planta Daninha, v. 19, n. 1, p. 135-143, 2001.

SILVA, M. A. S. Efeitos de períodos sem chuva, dosagens e volumes de aplicação de glyphosate no controle de Brachiaria decumbens Stapf. Botucatu: Universidade Estadual Paulista, 1996. 67p. Dissertação (Mestrado em Agronomia/Proteção de Plantas) - Universidade Estadual Paulista, 1996.

SOUZA, P. R.; FISCHER, M. M. Arroz vermelho: danos causados à lavoura gaúcha. Lav. Arroz., v. 39, p. 19-20, 1986.

VOLL, E. Efeitos da interação de ácido ferúlico e glyphosate em soja. Planta Daninha, v. 11, n. 1/2, p. 5-8, 1993.

YOKOYAMA, L. P.; RUCATTI, E. G.; KLUTHCOUSKI, J. Economia da produção: conjuntura, mercados e custos. In: VIEIRA, N. R. A.; SANTOS, A. B.; SANT'ANA, E. P. (Eds.) A cultura do arroz no Brasil. Santo Antônio de Goiás: EMBRAPA Arroz e Feijão, 1999. p.36-57. 